University of Wollongong

Research Online

Faculty of Engineering and Information

Faculty of Engineering and Information

Sciences - Papers: Part A

Sciences

$1-1-2015$

Interface analysis and hot deformation behaviour of a novel laminated composite with high-Cr cast iron and low carbon steel prepared by hot compression bonding

Zhengyi Jiang

University of Wollongong, jiang@uow.edu.au

Xingjian Gao

University of Wollongong, xg306@uowmail.edu.au

Sheng-Li Li

University of Science and Technology

Hong Mei Zhang

University of Science and Technology

Dengfu Chen

Chongqing University, chendfu@cqu.edu.cn

See next page for additional authors

Follow this and additional works at: https://ro.uow.edu.au/eispapers

Part of the Engineering Commons, and the Science and Technology Studies Commons

Research Online is the open access institutional repository for the University of Wollongong. For further information contact the UOW Library: research-pubs@uow.edu.au 


\title{
Interface analysis and hot deformation behaviour of a novel laminated composite with high-Cr cast iron and low carbon steel prepared by hot compression bonding
}

\begin{abstract}
A hot compression bonding process was developed to prepare a novel laminated composite consisting of high- $\mathrm{Cr}$ cast iron $(\mathrm{HCCl})$ as the inner layer and low carbon steel (LCS) as the outer layers on a Gleeble 3500 thermomechanical simulator at a temperature of $950{ }^{\circ} \mathrm{C}$ and a strain rate of $0.001 \mathrm{~S}^{-1}$. Interfacial bond quality and hot deformation behaviour of the laminate were studied by microstructural characterisation and mechanical tests. Experimental results show that the metallurgical bond between the constituent metals was achieved under the proposed bonding conditions without discernible defects and the formation of interlayer or intermetallic layer along the interface. The interfacial bond quality is excellent since no deterioration occurred around the interface which was deformed by Vickers indentation and compression test at room temperature with parallel loading to the interface. After well cladding by the LCS, the brittle $\mathrm{HCCl}$ can be severely deformed (about $57 \%$ of reduction) at high temperature with crack-free. This significant improvement should be attributed to the decrease of crack sensitivity due to stress relief by soft claddings and enhanced flow property of the $\mathrm{HCCl}$ by simultaneous deformation with the LCS.
\end{abstract}

\section{Keywords}

compression, prepared, steel, carbon, low, iron, interface, cast, cr, high, bonding, composite, novel, laminated, behaviour, deformation, hot, analysis

Disciplines

Engineering | Science and Technology Studies

\section{Publication Details}

Jiang, Z., Gao, X., Li, S., Zhang, H., Chen, D. \& Xu, J. (2015). Interface analysis and hot deformation behaviour of a novel laminated composite with high-Cr cast iron and low carbon steel prepared by hot compression bonding. Journal of Iron and Steel Research International, 22 (5), 438-445.

\section{Authors}

Zhengyi Jiang, Xingjian Gao, Sheng-Li Li, Hong Mei Zhang, Dengfu Chen, and Jian Zhong Xu 


\title{
Interface analysis and hot deformation behaviour of a novel laminated
}

\section{composite with high-Cr cast iron and low carbon steel prepared by hot}

\author{
compression bonding
}

\author{
Z.Y. Jiang ${ }^{1,2,{ }^{*}, \text { X.J. Gao }}{ }^{2,3,{ }^{*}, \mathrm{~S} \mathrm{Li}^{1} \text {, H. Zhang }}{ }^{1}$, D.F. $\mathrm{Chen}^{3}$, J.Z. Xu ${ }^{4}$ \\ (1. School of Materials Science and Engineering, University of Science and Technology Liaoning, Anshan, \\ Liaoning 114051, China; 2. School of Mechanical, Materials and Mechatronic Engineering, University of \\ Wollongong, Wollongong NSW 2522, Australia; 3. College of Materials Science and Engineering, Chongqing \\ University, Chongqing 400044, China; 4. State Key Laboratory of Rolling and Automation, Northeastern \\ University, Shenyang, Liaoning 200941, China)
}

\begin{abstract}
A hot compression bonding process was developed to prepare a novel laminated composite consisting of high-Cr cast iron (HCCI) as the inner layer and low carbon steel (LCS) as the outer layers on a Gleeble 3500 thermomechanical simulator at temperature of $950{ }^{\circ} \mathrm{C}$ and strain rate of $0.001 \mathrm{~s}^{-1}$. Interfacial bond quality and hot deformation behaviour of the laminate were studied by microstructural characteristics and mechanical tests. Experimental results show that the metallurgical bond between the constituent metals was achieved under the proposed bonding conditions without discernible defects and the formation of interlayer or intermetallic layer along the interface. The interfacial bond quality is excellent since no deterioration occurred around the interface where was deformed by Vickers indentation and compression test at room temperature with parallel loading to the interface. After well cladding by the LCS, the brittle HCCI can be severely deformed ( $57 \%$ of reduction) at high temperature with crack-free. This significant improvement should be attributed to the decrease of crack sensitivity due to stress relief by soft claddings and enhanced flow property of the HCCI by simultaneous deformation with the LCS.
\end{abstract}

Keywords: Bonding; Laminated metal composite; Interface structure; Hot working; High-Cr cast iron

\section{Introduction}

Laminated metal composites (LMCs) have drawn considerable research attention over the past two decades due to their unique properties including advanced mechanical performance and virtuous complementarity between the constituent metals ${ }^{[1-16]}$. Fabrication of materials in the form of laminated structure with immaculate interfacial bond can significantly improve many properties such as fracture toughness, impact resistance, fatigue behaviour and damping capacity; or provide enhanced ductility or

* Corresponding author: Z.Y. Jiang
X.J. Gao
Email: jiang@uow.edu.au

Email:xg306@uowmail.edu.au 
formability for otherwise brittle material ${ }^{[1,2]}$. Based on the advantages, increasing efforts have been focused on improving the workability of the brittle metal or alloy by means of lamination with the ductile material $^{[5,6]}$.

It is well known that high-Cr cast irons (HCCIs) possess high hardness and excellent wear resistance with inherent server brittleness because of the microstructural characteristics consisting of massive hard carbides in the ferrous matrix ${ }^{[17-19]}$. High crack sensitivity derived from the brittleness results in an inferior deformability of the HCCIs. Hence the shaping of them is usually carried out by casting technology or spray forming in liquid state. Although some investigations have concentrated on the development of the laminated components with HCCI and low carbon steel (LCS) or medium carbon steel (MCS) prepared by cast or diffusion bonding $[4,15,16,20-22]$ to improve their impact resistance, the workability of the brittle HCCI with ductile metallic lamination has not been discussed till now. It is worth mentioning that the laminated components such as bimetal hammer, composite liner and cladding roller have been used in applications where require excellent wear resistance and sufficient toughness.

Compared with the cast and diffusion bonding, hot compression bonding such as rolling and forging processes is more effective and efficient. It can not only produce the large scale LMCs at a lower cost with higher productivity, but also improve the mechanical properties of the constituent metals and synthetically performance of the composite by refining the microstructure or developing the preferred macro / micro texture during plastic deformation. In this study, a hot compression bonding process was explored to fabricate a novel sandwich structural LCS / HCCI / LCS laminate. Interfacial bond quality was analysed by microstructural observations and mechanical tests. The hot deformation behaviour of the HCCI with and without lamination was compared to elucidate its workability.

\section{Material and experimental procedure}

\subsection{Material}

The chemical composition and Vickers hardness of the raw materials are listed in Table 1, in which the HCCI (in as-cast state) is characterised by high hardness and stiffness, whereas the LCS (in hot-rolled state) with low hardness implies excellent toughness and ductility. Masahashi et al. ${ }^{[5,6]}$ reported that simultaneous deformation together with soft material is a beneficial method to deform hard material by stress relief, even though the plastic instabilities in one of the components happen 
earlier than the other one due to prominent differences in mechanical properties ${ }^{[23]}$. Fig. 1(a) and (b) shows the initial microstructures of the LCS and the HCCI, respectively. It can be seen that from Fig. 1(a), the LCS consists of high volume fraction of ferritic structure with fine grain size and a small quantity of pearlitic patches located at trilateral positions. This microstructure will transform to fully austenite at high temperature, and then imparts a favourable flow ability to the LCS. On the other hand, Fig. 1(b) presents the typical microstructure of the HCCI by the presence of large hexagonal primary $\mathrm{M}_{7} \mathrm{C}_{3}$ carbides and interdendritic eutectic $\mathrm{M}_{7} \mathrm{C}_{3}$ carbides in a matrix of martensite with retained austenite. These hard carbides contribute to outstanding wear resistance, but meanwhile severely deteriorate the workability of the HCCI.

Table 1 Chemical composition (wt \%) and Vickers hardness (HV) of HCCI and LCS.

\begin{tabular}{ccccccccc|c}
\hline Material & $\mathrm{C}$ & $\mathrm{Si}$ & $\mathrm{Mn}$ & $\mathrm{P}$ & $\mathrm{S}$ & $\mathrm{Cr}$ & $\mathrm{Ni}$ & $\mathrm{Mo}$ & Hardness \\
\hline HCCI & 2.4 & 1.2 & 0.9 & 0.02 & 0.03 & 23.0 & 0.3 & 0.5 & $868 \pm 50$ \\
LCS & 0.1 & 0.15 & 1.61 & 0.014 & 0.002 & 0.21 & $\backslash$ & $\backslash$ & $176 \pm 3$ \\
\hline
\end{tabular}
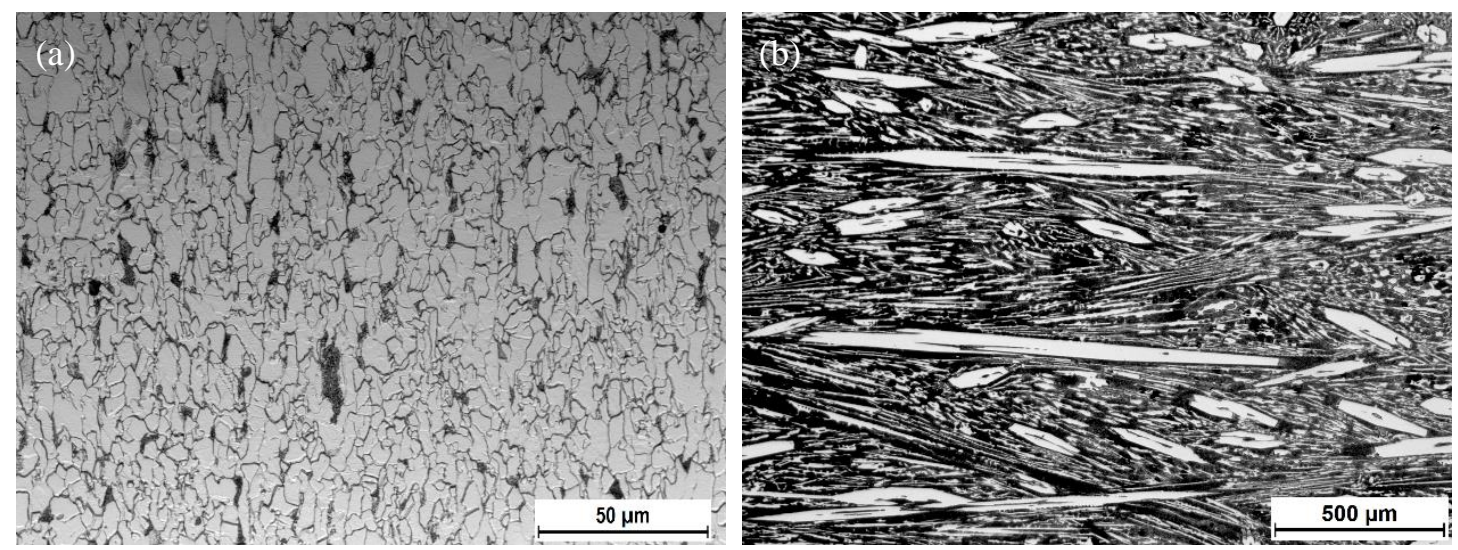

Fig. 1. Initial microstructures of the constituent metals of the laminated composite: (a) LCS, (b) HCCI.

\subsection{Hot compression bonding test}

In order to simulate hot roll or forge bonding processes, a Gleeble 3500 thermomechanical simulator was employed to carry out the laminated bonding test. It is recognised that the Gleeble is a dynamic testing machine which can simulate a wide variety of thermal-mechanical metallurgical situations ${ }^{[24]}$. According to the requirement of the simulator, the specimens of HCCI and LCS was cut into cylinders with dimensions of $\Phi 10 \times 6 \mathrm{~mm}$ and $\Phi 10 \times 3 \mathrm{~mm}$, respectively. 
Prior to bonding test, all the contact surfaces were polished to $1 \mu \mathrm{m}$ and cleaned by ethanol. Set of three specimens, one layer HCCI placed in the middle with two layers LCS placed on the both sides, were stacked into a sandwich structural assembly. The assembly was put in the testing chamber and a uniaxial compression ( 2.5 MPa of applied stress) was employed at room temperature to ensure good contact between the specimens. Afterwards the temperature was raised to $950{ }^{\circ} \mathrm{C}$ at a heating rate of 5 ${ }^{\circ} \mathrm{C} / \mathrm{s}$. This temperature was determined by dilatometric test of the monolithic HCCI with the same thermal history. Fig. 2 shows the variation of the thermal expansion coefficient as a function of temperature, which indicates a solid-state phase transition occurred in $824-887{ }^{\circ} \mathrm{C}$ where the matrix was austenitised. Followed by $5 \mathrm{~min}$ for homogenisation, hot compression bonding was conducted with $70 \%$ of overall reduction at an equivalent strain rate of $0.001 \mathrm{~s}^{-1}$. Once the bonding process was completed the laminated composite was cooled by air jet to room temperature before removal from the chamber.

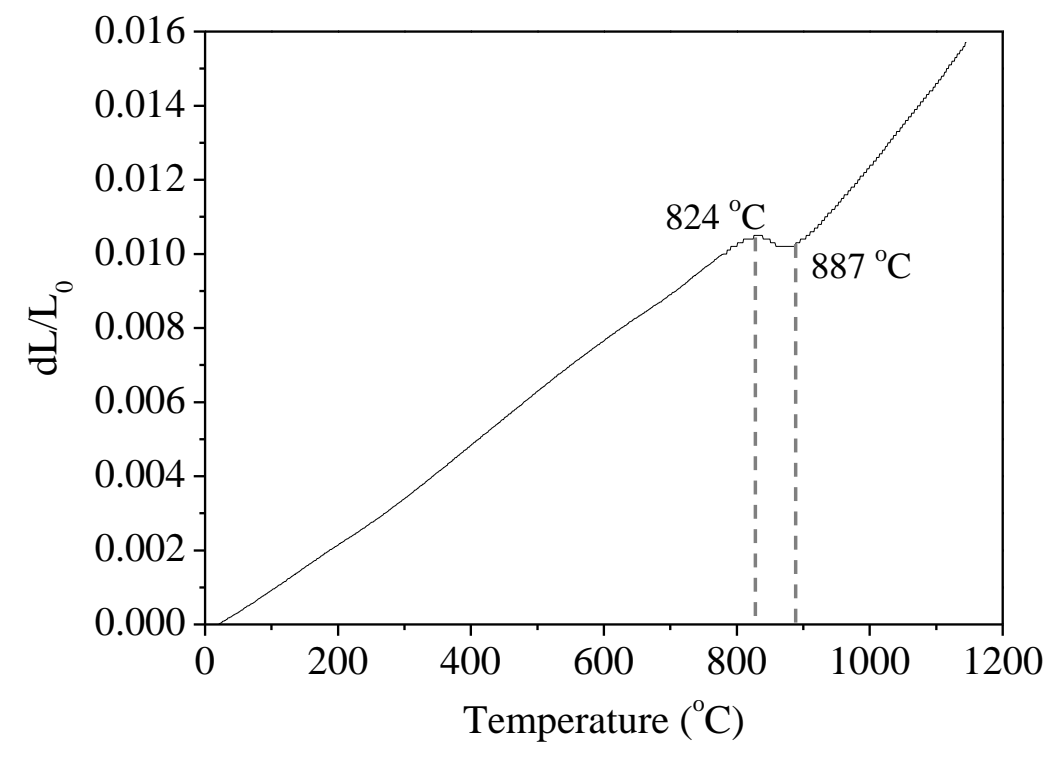

Fig. 2. Thermal dilatometric curve of the HCCI.

\subsection{Microstructural characterisation and mechanical test}

After fabrication, the laminated composite was cut and analysed through optical microscope (OM) and scanning electron microscope (SEM) equipped with Energy Dispersive X-ray Spectroscopy (EDS) to study microstructures. The quality of the HCCI layer with severe plastic deformation was examined in two directions, viz. ND-TD plane which is perpendicular to the interface and RD-TD plane which is parallel to the interface. Microhardness profile across the interface was obtained by Vickers hardness 
testing machine using a load of $100 \mathrm{~g}$ and dwell time of $10 \mathrm{~s}$. Moreover, compression test at room temperature and Vickers indentation were performed to evaluate the bonding strength. The compression test was proceeded on a cuboid sample with loading parallel to the interface at an equivalent strain rate of $0.001 \mathrm{~s}^{-1}$. The sample with dimensions of $7.5 \times 5 \times 3.5 \mathrm{~mm}$ was machined from the laminated composite. Vickers indentation was conducted near the interface at the LCS side ${ }^{[25-27]}$ by $500 \mathrm{~g}$ loading for $10 \mathrm{~s}$, and then was examined by SEM.

\section{Results and discussion}

\subsection{Interfacial bond quality}

Various studies have demonstrated that interfacial bond can significantly affect the overall performance of composite materials ${ }^{[25-28]}$. Hence it is of vital importance to assess the bonding quality of the current laminated composite. In hot compression bonding process, due to the combined action of pressure and heat over short periods, the reactions between the constituent metals involve three stages: (i) development of physical contact and initialisation of elements diffusion before hot compression, (ii) activation of the surfaces in contact by minor plastic deformation, which creates a mechanical bond with linear interface, (iii) interpenetration along the interface results in the formation of interfacial waves by increment of plastic deformation. Moreover, interlayer or intermetallic layer within the interface ${ }^{[29]}$ probably generates in these stages once thermodynamic and kinetic conditions are satisfied.

Fig. 3(a) and (b) shows the interfacial structure of the laminated composite using OM and SEM, respectively. The differences in contrast and microstructure between the LCS and the HCCI clearly reveal the interface with wavy shape. Previous research ${ }^{[30,31]}$ on explosive welding of LMCs have reported that the wavy joint is beneficial to improve the bonding strength. Eroglu and Kurt ${ }^{[16]}$ also produced a HCCI / LCS laminate in solid-state by diffusion bonding at temperature range of 900-1100 ${ }^{\circ} \mathrm{C}$. The results turned out that the interface is linear shape without plastic deformation. As shown in Fig. 3(a) and (b), although the interfacial morphology is non-linear, the interface has a good bonding quality between the constituent metals since no defect such as micro crack and lack of bonding was detected. Fig. 3(a) represents the microstructural changes after hot compression bonding. In the LCS side, the grain size was inhomogeneous and the grain shape became anomalous. While in the HCCI 
side, primary and eutectic carbides as well as ferrous matrix were refined with varying degrees. The secondary carbides precipitated in the HCCI layer were observed in Fig. 3(b).
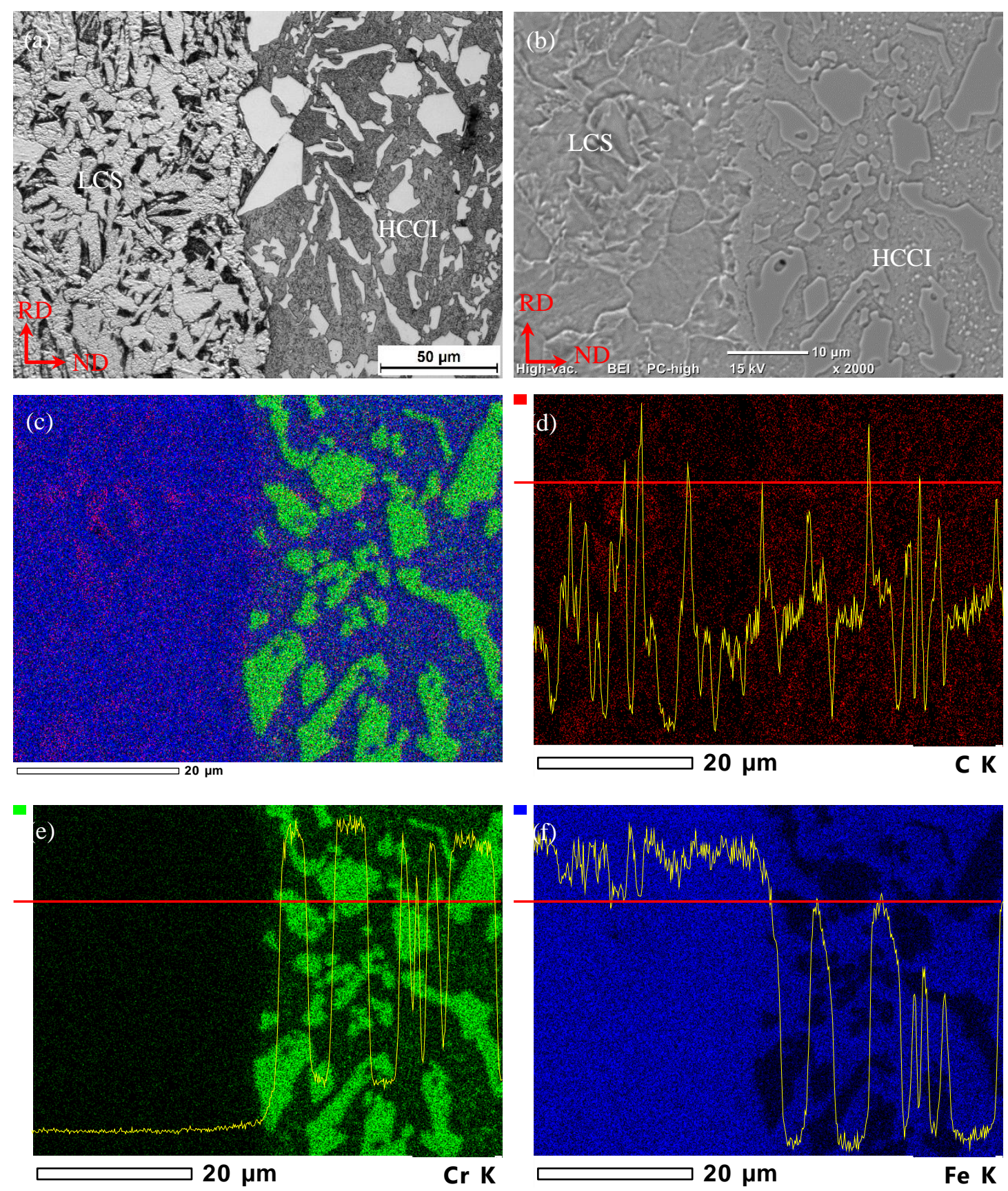

Fig. 3. OM and SEM micrographs of the bonding interface of the laminated composite: (a) OM micrograph, (b) SEM micrograph under the backscatter electron, (c) EDS mapping of (b), (d) C map and line analyses, (e) Cr map and line analyses, (f) Fe map and line analyses. 
In addition, it is worth mentioning that no micrometre-scale interlay or intermetallic layer was found within the interface from Fig. 3(a) and (b). This observation was further testified by EDS analyses as shown in Fig. 3(c)-(f). The distinct division of X-ray maps and the step change of line scanning of $\mathrm{Cr}$ and Fe reveal that the elements diffusion between the constituent metals during the bonding process was very limited. On the one hand, the limited atomistic mixing of the interface occurred without apparent changes in the characteristics of the raw materials. Fig. 4 shows the microhardness variation across the interface of the laminated composite. It can be noted that the hardness values of the LCS side and the HCCI side slightly decreased and increased, respectively, than their initial hardness. The former could be attributed to the changes of grain morphology like size and shape, while the latter results from the refinement of microconstituents including carbides and matrix. On the other hand, the gradient of mechanical properties across the interface was accommodated somewhat due to the narrow diffusion. As shown in Fig. 4, the hardening on the LCS side and the softening on the HCCI side are recognised around the interface. Therefore, the metallurgical bonding rather than mechanical or chemical bonding was achieved under the hot compression conditions.

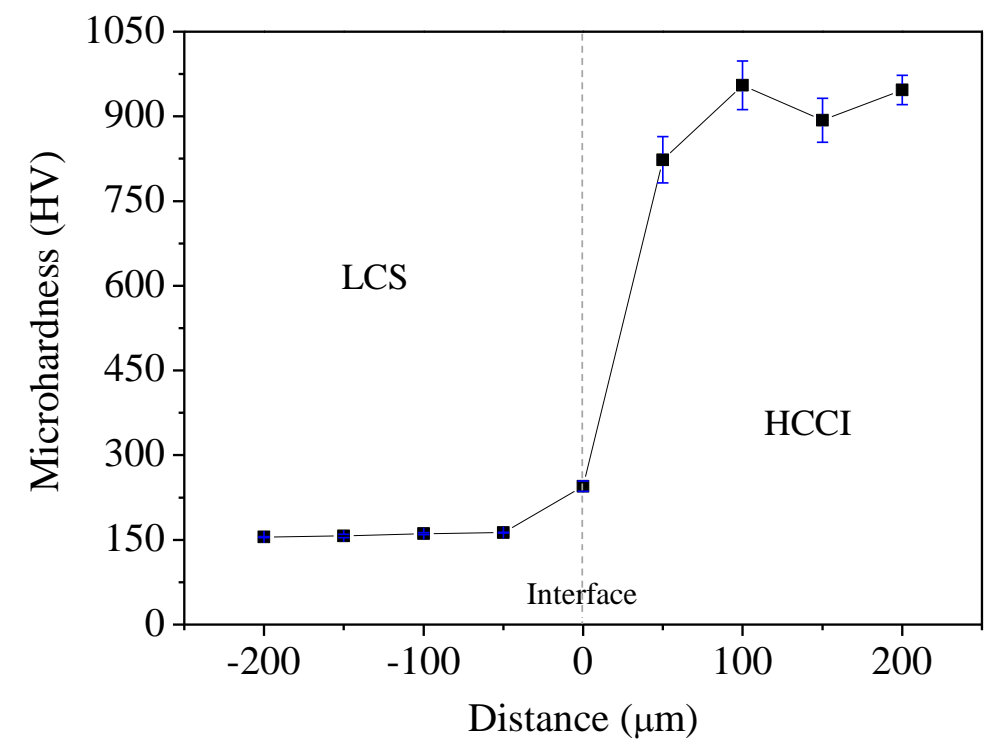

Fig. 4. Microhardness variation across the interface of the laminated composite.

Fig. 5(a) shows the true stress-strain curve of the cuboid laminated sample subjected to compression test at room temperature with loading parallel to the interface. It is noted that the flow stress increased with true strain up to a maximum value that was followed by a sharp decrease. This 
sudden change was attributed to the contact lost between the sample and anvil because of fracture failure. Fig. 5(b) presents 3-D image of the cuboid sample after compression using M205A Stereo Microscope. The image was taken by piling up the tearing fragments, which displays the principal feature during quasi-static loading in parallel direction was parallel cracks propagating within the HCCI layer. Fig. 5(c) shows SEM micrograph of the characteristic fracture surface of the HCCI layer. It is seen that the cleavage planes of the carbide phase are the preferred path for crack propagation. The fracture behaviour of the laminated composite implies that the tensile stress perpendicular to the interface was very strong. However, neither crack nor delamination was detected along the interface, which indicates a reliable bond quality.
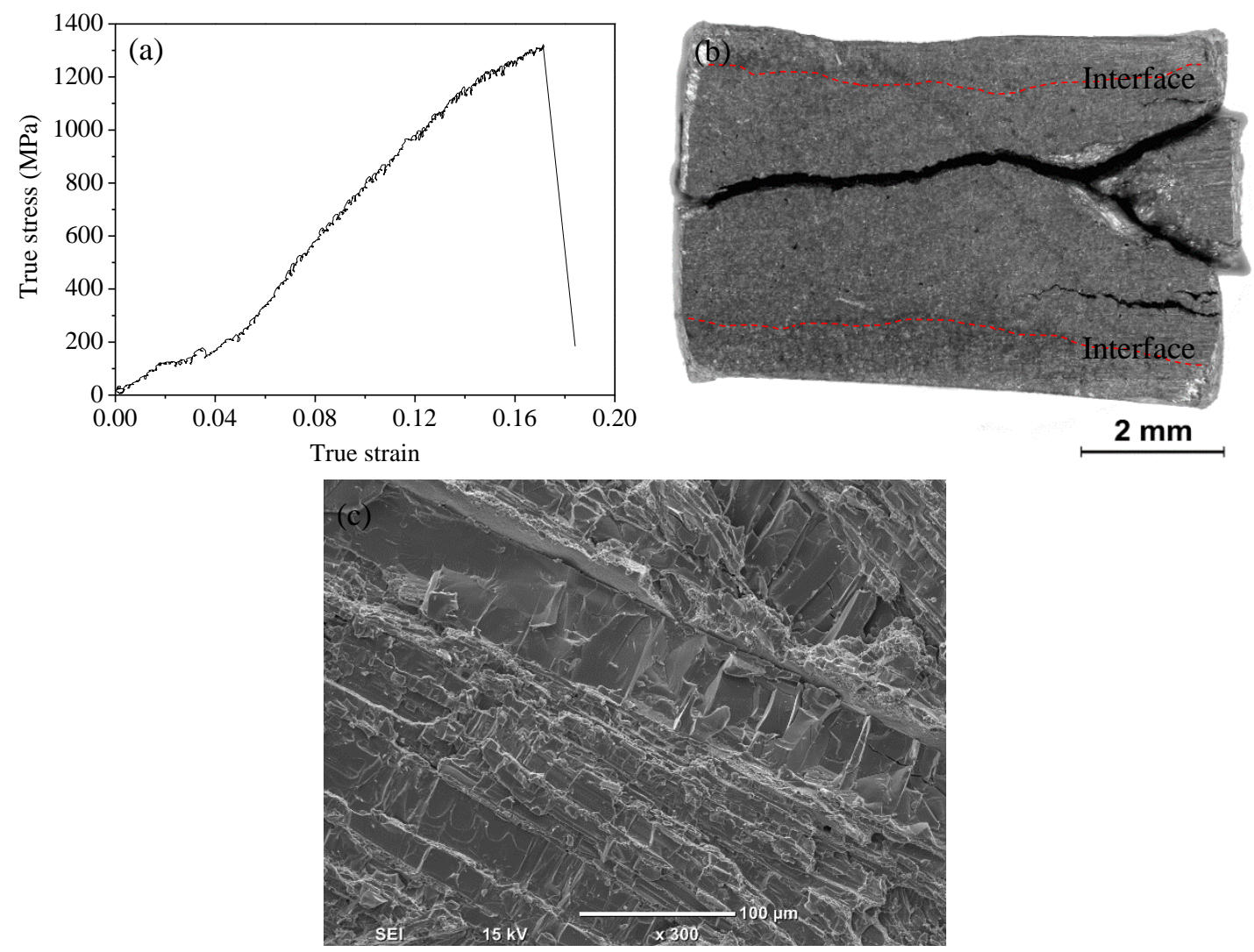

Fig. 5. True stress-strain curve of the cuboid sample compressed at room temperature (a), 3-D image of the cuboid sample after compression (b), SEM micrograph showing typical fracture surface of the HCCI layer.

Fig. 6 shows the Vickers indentation in the vicinity of the interface to further assess the bonding strength. Although this method is qualitative in its nature, it is useful for inspecting interfacial bond 
quality in micro-scale. As is seen in low (Fig. 6(a)) and high (Fig. 6(b)) magnifications, no crack or debonding is observed around the joint interface deformed by indention. Therefore, it can be confirmed that the bonding strength obtained by the hot compression bonding process is excellent.
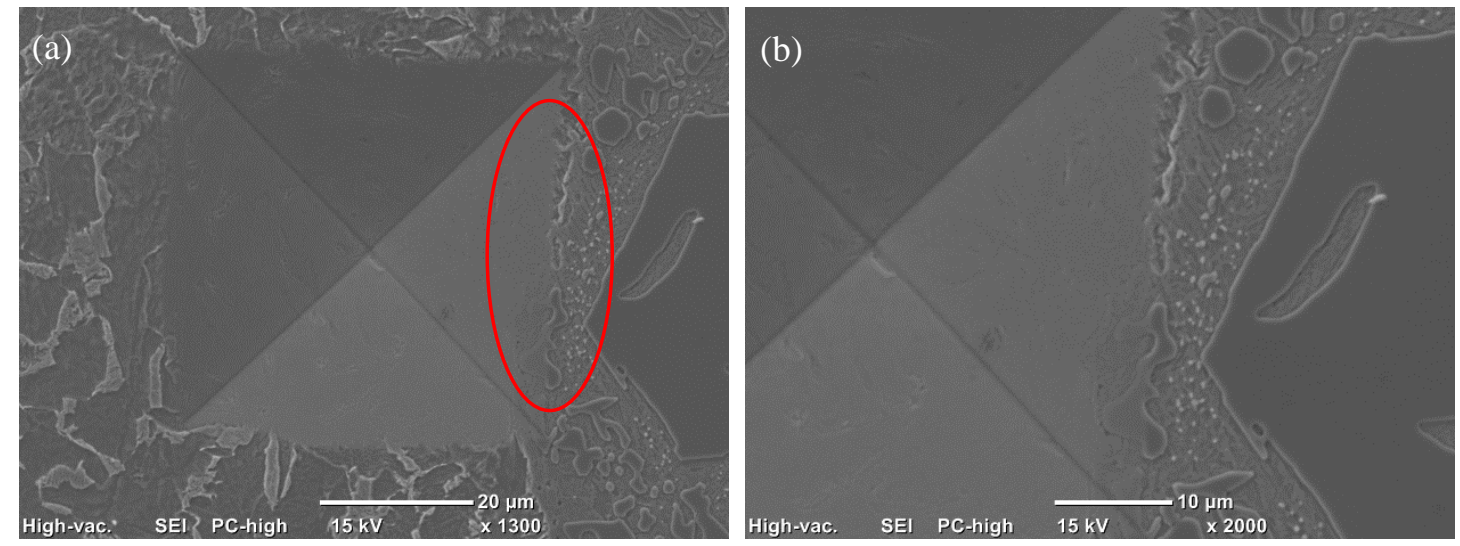

Fig. 6. SEM micrographs of Vickers indentation near the interface at the LCS side: (a) morphology of indentation, (b) micrograph of the selected region.

\subsection{Hot deformation of the laminate}

Fig. 7 shows the macrostructure of the HCCI / LCS laminated composite. A sandwich structure is clearly observed with wavy interfaces. The small wave amplitude indicates that the plastic deformation on both LCS and HCCI layers are quasi-uniform. The partial reductions of the HCCI and the LCS are about $57 \%$ and $82 \%$, respectively, which were calculated by averaging ten measurements using the image analysis technique. Furthermore, it was found that the LCS layers were extruded from the laminate. This is in line with the characteristics of the isostress behaviour of the laminate in which each constituent layer is subjected to the same stress ${ }^{[1]}$.

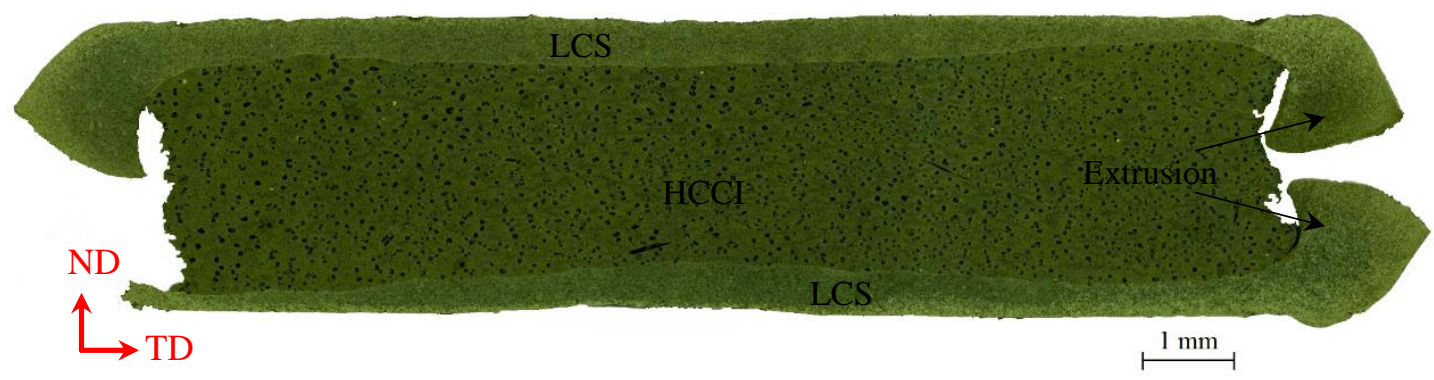

Fig. 7. Macrograph of the HCCI / LCS laminated composite. 
To verify the quality of the HCCI layer after hot compression bonding, microstructural evolutions of this layer in ND-TD plane and RD-TD plane were examined by OM as shown in Fig. 8(a) and (b), respectively. As reported in previous section (Fig. 3 (a) and (b)), primary and eutectic carbides as well as ferrous matrix were refined with varying degrees due to plastic deformation, while secondary carbides precipitated because of austenite destabilisation ${ }^{[32]}$ during thermomechanical treatment. In addition, one more significant finding is no discernible cracks can be found in this brittle layer, which means that the HCCI was successfully deformed with crack-free under the soft cladding conditions.
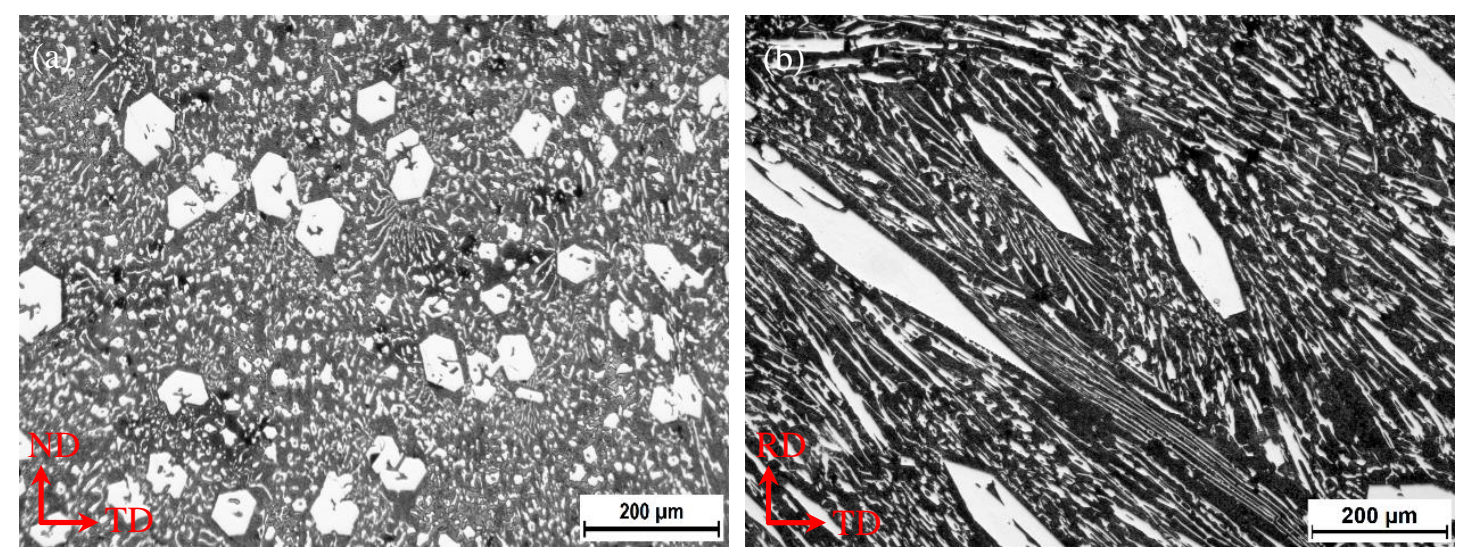

Fig. 8. OM micrographs of the HCCI layer after hot compression bonding: (a) ND-TD plane, (b)

RD-TD plane.

As a comparison, the monolithic HCCI cylindrical sample with $6 \mathrm{~mm}$ length and $4 \mathrm{~mm}$ diameter was prepared and subjected to isothermal compression test at temperature of $950{ }^{\circ} \mathrm{C}$ and strain rate of $0.001 \mathrm{~s}^{-1}$. The overall reduction was $60 \%$ of length even though the fracture may occur at a small plastic strain. Fig. 9 shows 3-D images of the sample after hot compression using M205A Stereo Microscope. Apparently, severe macro cracks (Fig. 9(b)) were observed with excessive barreling and unstrained base surface (Fig. 9(a)), which manifests the inferior deformability of the HCCI without soft claddings. The principal crack having an approximately $55^{\circ}$ angle to the base surface throughout the thickness indicates that the shear stress within the sample was strong even under a uniaxial compression load. As a consequence, one might draw the conclusion that the workability of the brittle HCCI was significantly improved by cladding with the ductile LCS. Xie et al. ${ }^{[22]}$ investigated the hot rolling performance of a $\mathrm{HCCI}$ with lower $\mathrm{Cr}$ content $\left(12.77\right.$ wt \%) at higher temperature $\left(1150{ }^{\circ} \mathrm{C}\right)$ 
after cast cladding by LCS. The results briefly suggested that the "lubricating effect" derived from LCS claddings is beneficial to the deformation of HCCI.

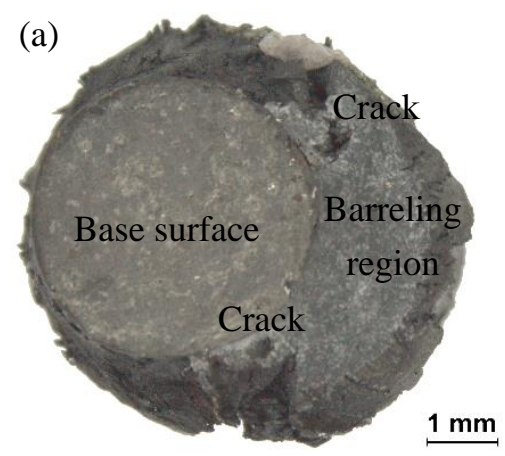

(b)

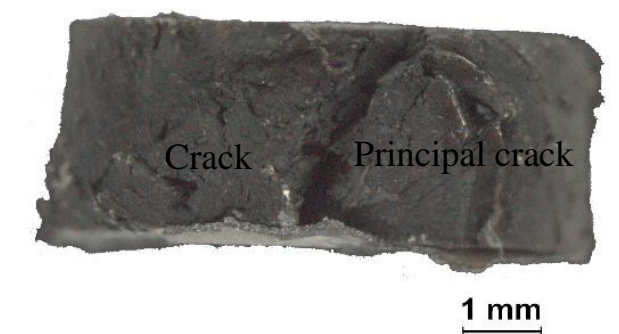

Fig. 9. 3-D images of the monolithic HCCI after hot compression: (a) Top view, (b) Side view.

Fig. 10 shows the true stress-strain curves of the monolithic HCCI and the laminated composite subjected to hot compression process. Although the flow pattern of the laminated composite is different from that of the HCCI layer, it can help us to gain a fundamental understanding of variation of the flow stress during plastic deformation. As can be seen, the true stress of the monolithic HCCI increases dramatically within a small range of true strain $(\varepsilon \leq 0.1)$ and reaches to a peak value of $\sim 270 \mathrm{MPa}$. Such a rapid change indicates that the HCCI is hypersensitivity of crack due to the effects of stress concentration. The following sharp decrease of the stress ascribes to the crack generation and propagation which destroyed the continuity of the material so as to a drastic decrease of the uniaxial compression load. However, the true stress-strain curve of the laminated composite shows a different flow pattern in three typical features: (i) the flow behaviour is mild without stress saltation, which is conducive to reduce the crack sensitivity, (ii) the peak value of the true stress is $\sim 108 \mathrm{MPa}$ at true strain of $\sim 0.4$. Considerable lower stress combined with higher plastic strain signifies the soft claddings contributed to stress relief during simultaneous deformation ${ }^{[5,6]}$. (iii) A steady state rather than a sharp decrease of the true stress is displayed over the peak value. 


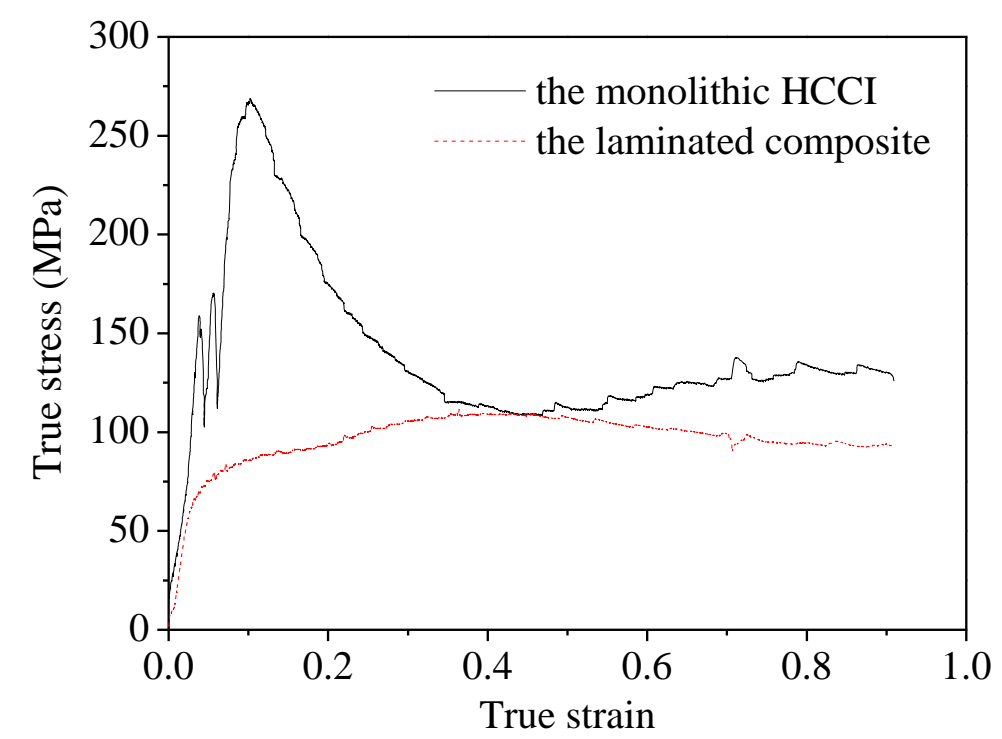

Fig. 10. True stress-strain curves of the monolithic HCCI and the laminated composite subjected to hot compression process.

Fig. 11 shows the principle of hot compression process by illustrating the isostress behaviour of the monolithic HCCI and the well-bonded laminated composite. It is well known that the crack occurred because flow stress or plastic strain exceeds the critical value. For hot compression on the monolithic HCCI, the base surface of the sample not only sustained normal stress $\left(\sigma_{n}\right)$, but also suffered from centripetal shear stress $\left(\sigma_{\tau}\right)$ due to the friction between sample and anvil. Combined with its inferior flow ability, the sample was prone to barreling, and the lateral cracks (Fig. 9) occurred once shear stress in the barreling region over the critical value.

However, the deformation mode was changed dramatically in the form of lamination. As shown in Fig. 11, the deformation behaviour of the laminated composite can be understood from the strain rate-stress response of the individual layers [1]. Since the LCS has an excellent solid flow ability at high temperature, it was preferentially deformed and even extruded from the laminate (Fig. 7). This preferred deformation tended to enforce the simultaneous deformation of the HCCI layer because of the strong interfacial bond. Hence a tensile stress $\left(\sigma_{t}\right)$ acted on the base surface of the HCCI layer which contributed to its extension. This extension effectively reduced the barreling effect on the one hand, and decreased the normal stress $\left(\sigma_{n}^{\prime}\right)$ on the other hand. As a result, the brittle HCCI might be flow like a ductile metal within the laminated composite. 


Before compression

Fig. 11. Schematic diagram of hot compression on the monolithic HCCI and the laminated composite.

\section{Conclusions}

A novel sandwich structural HCCI / LCS laminated composite was fabricated by hot compression bonding process using a Gleeble 3500 thermomechanical simulator. The interfacial bond quality between the constituent metals and hot workability of the brittle HCCI were investigated in this paper. The following conclusions are obtained:

(1) Hot compression bonding process is a suitable method to produce the HCCI / LCS laminated composite under the proposed processing conditions. The metallurgical bond between the constituent metals was achieved at $950{ }^{\circ} \mathrm{C}$ without the formation of detectable interlay and intermetallic layer.

(2) Interfacial bond quality of the laminated composite is excellent because no defects can be found around the interface. Compression test of the cuboid laminated sample with parallel loading to the interface at room temperature shows a reliable bond quality, and Vickers indentation close to the interface reveals high bonding strength.

(3) The formability of the brittle HCCI was significantly improved by simultaneous deformation with the ductile LCS in the form of well-bonded laminated composite. The soft claddings contributed to stress relief during deformation so as to decrease the crack sensitivity. Moreover, the sound 
interfacial bond changed the hot deformation behaviour of the HCCI and made it flow like a ductile material.

\section{Acknowledgements}

The first author acknowledges the China Scholarship Council (CSC) and UOW IPTA for supporting the current study. The authors are grateful to Mr Bob de Jong and Dr Liang Chen for the help of hot compression bonding tests.

\section{References}

[1] D.R. Lesuer, C.K. Syn, O.D. Sherby, J. Wadsworth, J.J. Lewandowski, W.H. Hunt Jr., Int. Mater. Rev. 41 (1996) $169-197$.

[2] J. Wadsworth, D.R. Lesuer, Mater. Charact. 45 (2000) 289-313.

[3] E. Takeuchi, M. Zeze, H. Tanaka, H. Harada, S. Mizoguchi, Ironmak. Steelmak. 24 (1997) 257-263.

[4] H. Oh, S. Lee, J.Y. Jung, S. Ahn, Metall. Mater. Trans. A 32 (2001) 515-524.

[5] N. Masahashi, S. Watanabe, S. Hanada, K. Komatsu, G. Kimura, Metall. Mater. Trans. A, 37 (2006) 1665-1673.

[6] N. Masahashi, K. Komatsu, S. Watanabe, S. Hanada, J. Alloy Compd. 379 (2004) 272-279.

[7] L. Zhang, L. Meng, S.P. Zhou, F.T. Yang, Mater. Sci. Eng. A 371 (2004) 65-71.

[8] G. Heness, R. Wuhrer, W.Y. Yeung, Mater. Sci. Eng. A 483-484 (2008) 740-742.

[9] M. Pozuelo, F. Carreno, C.M. Cepeda-Jimenez, O.A. Ruano, Metall. Mater. Trans. A 39 (2008) 666-671.

[10] M. Pozuelo, F. Carreno, O.A. Ruano, Compos. Sci. Technol. 66 (2006) 2671-2676.

[11] C.Y. Liu, Q. Wang, Y.Z. Jia, R. Jing, B. Zhang, M.Z. Ma, R.P. Liu, Mater. Sci. Eng. A 556 (2012) 1-8.

[12] X.B. Li, G.Y. Zu, P. Wang, Mater. Sci. Eng. A 575 (2013) 61-64.

[13] X.B. Li, G.Y. Zu, P. Wang, Mater. Sci. Eng. A 562 (2013) 96-100.

[14] B. Kurt, A. Calik, Mater. Charact. 60 (2009) 1035-1040.

[15] B. Kurt, M. Eroglu, Sci. Technol. Weld Joi. 12 (2007) 467-471.

[16] M. Eroglu, B. Kurt, Mater. Sci. Tech-Lond 23 (2007) 171-176.

[17] A. Bedolla-Jacuinde, M.W. Rainforth, I. Mejia, Metall. Mater. Trans. A 44 (2013) 856-872.

[18] A. Wiengmoon, J.T.H. Pearce, T. Chairuangsri, Mater. Chem. Phys. 125 (2011) 739-748.

[19] B.J. Chung, X. Tang, D.Y. Li, B. Hinckley, K. Dolman, Wear 267 (2009) 356-361.

[20] B.W. Xiong, C.C. Cai, H. Wan, B.P. Lu, Mater. Design 32 (2011) 2978-2982.

[21] B.W. Xiong, C.C. Cai, B.P. Lu, J. Alloy Compd. 509 (2011) 6700-6704.

[22] G.L. Xie, J.T. Han, J. Liu, Z.Y. Jiang, Mater. Sci. Eng. A 527 (2010) 6251-6254

[23] M. Talebian, M. Alizadeh, Mater. Sci. Eng. A 590 (2014) 186-193.

[24] Defining a New Era in Physical Simulation and Thermal-Mechanical Testing, http://gleeble.com.

[25] H. Zhang, Q. Chen, D.Y. Li, Acta. Mater. 52 (2004) 2037-2046.

[26] H. Zhang, D.Y. Li, Acta. Mater. 56 (2008) 6197-6204.

[27] H. Zhang, D.Y. Li, Surf. Coat. Tech. 197 (2005) 137-141.

[28] S. Nambu, M. Michiuchi, J. Inoue, T. Koseki, Compos. Sci. Technol. 69 (2009) 1936-1941.

[29] M. Konieczny, Mater. Sci. Eng. A 586 (2013) 11-18. 
[30] H.R. Zareie Rajani, S.A.A. Akbari Mousavi, Mater. Sci. Eng. A 556 (2012) 454-464.

[31] K. Raghukandan, J. Mater. Process. Tech. 139 (2003) 573-577.

[32] J. Wang, C. Li, H.H. Liu, H.S. Yang, B.L. Shen, S. Gao, S.J. Huang, Mater. Charact. 56 (2006) 73-78. 